15. McCurdy JD, Enders FT, Jones A et al. Detection of cytomegalovirus in patients with inflammatory bowel disease: where to biopsy and how many biopsies? Inflamm Bowel Dis 2015;21:2833-8.

${ }^{1}$ EA-3064, Groupe Immunité des Muqueuses et Agents Pathogènes (GIMAP), Faculty of Medicine of Saint-Etienne, University of Lyon, Lyon, France; ${ }^{2}$ Laboratory of Infectious Agents and Hygiene, University-Hospital of Saint-Etienne, Saint Etienne, France; ${ }^{3}$ Department of Gastroenterology, University-Hospital of Saint-Etienne, Saint Etienne, France. Correspondence: Xavier Roblin, MD, PhD, Department of Gastroenterology, University -Hospita of Saint-Etienne, 42055 Saint Etienne cedex 02,

France.

E-mail: xavier.roblin@chu-st-etienne.fr

\section{Fecal Microbiota Transfer in Patients With Chronic Antibiotic- Refractory Pouchitis}

Andreas Stallmach, $\mathrm{MD}^{1}$, Kathleen Lange, $\mathrm{MD}^{1}$, Juergen Buening, $\mathrm{MD}^{2}$, Christian Sina, $\mathrm{MD}^{2}$, Marius Vital, $\mathrm{PhD}^{3}$ and Dietmar $\mathrm{H}$. Pieper, $\mathrm{PhD}^{3}$

doi:10.1038/ajg.2015.436

To the Editor: Fecal microbiota transfer (FMT) may be an alternative approach to classical treatment in ulcerative colitis (UC) and chronic pouchitis. Very recently, Moayyedi et al. (1) reported that FMT is effective for inducing remission in mildto-moderate UC compared with a placebo in a randomized controlled trial. However, in a second study by Rossen et al. (2), no positive effects were observed after FMT. In contrast to the rather moderate effects of FMT on the course of UC, FMT for chronic pouchitis might be a more promising approach, given the documented role of bacteria in the pathogenesis. After restorative proctocolectomy and ileal pouch-anal anastomosis (IPAA), pouchitis is the most common long-term complication affecting up to $50 \%$ of UC patients. The pathogenesis of pouchitis remains incompletely elucidated; however, anaerobic bacterial overgrowth and/or dysregulation of the mucosal immune response are postulated reasons. The response to antibiotics of patients with pouchitis supports the concept of a causal relationship between pouch dysbiosis and inflammation. However, a recently published study on eight patients with chronic pouchitis described no beneficial clinical response after a single FMT (3).

In our study, five patients received three or more cycles with metronidazole and ciprofloxacin for at least 10 days to treat pouchitis after IPAA. After initial improvement, symptoms soon relapsed and all patients progressed into chronic antibiotic-refractory pouchitis. After excluding secondary courses of pouchitis using endoscopy, pelvic MRT, and stool investigation for pathogens including $C$. difficile, all patients were treated by FMT with an interval of 3-4 weeks. Pouchoscopies were performed before and within 3 months after the first FMT, and inflammation was scored using the composite pouchitis disease activity index (PDAI) (4). In three patients, pouch inflammation was additionally assessed by fecal calprotectin (FC) levels before FMT and during follow-up.

Stool samples for FMT derived from two unrelated healthy donors whose stool and blood samples were screened for human immunodeficiency virus 1 and 2, syphilis, viral hepatitis A, B, and C, C. difficile, Giardia lamblia, and other enteric pathogens. Donor stools were collected on the day of FMT. A measure of $150 \mathrm{~g}$ of stool was homogenized with $400 \mathrm{ml}$ of isotonic sodium chloride. Afterward, the homogenate was filtered repeatedly through a sterile gauze pad. The finished stool slurry was divided in two portions: one was immediately transferred to the endoscopy unit and administered into the jejunum during upper gastrointestinal tract endoscopy, and the other was stored at $-80^{\circ} \mathrm{C}$ after

Table 1. Baseline characteristics of patients with pouchitis and outcome after FMT

\begin{tabular}{|c|c|c|c|c|c|c|c|}
\hline $\begin{array}{l}\text { Patient, sex, } \\
\text { age (years) }\end{array}$ & $\begin{array}{l}\text { Pouch age } \\
\text { (months) }\end{array}$ & $\begin{array}{l}\text { Previous } \\
\text { antibiotic } \\
\text { treatment }\end{array}$ & $\begin{array}{l}\text { Number } \\
\text { of FMTs }\end{array}$ & $\begin{array}{l}\text { PDAI (symptoms+ } \\
\text { endoscopy+histology) } \\
\text { before first FMT }\end{array}$ & $\begin{array}{l}\text { PDAI (symptoms+ } \\
\text { endoscopy+histology) } \\
\text { after last FMT }\end{array}$ & $\begin{array}{l}\text { FC before/after } \\
\text { last FMT }\end{array}$ & $\begin{array}{l}\text { Outcome/follow-up } \\
\text { after last FMT }\end{array}$ \\
\hline $\begin{array}{l}\text { 1. J. M., } \\
\text { female, } 32\end{array}$ & 16 & $\begin{array}{l}\text { Cipro } \\
\text { Metro } \\
\text { Rifaximin }\end{array}$ & 1 & $4+4+2=10$ & $2+2+1=5$ & $566 / 47$ & Remission for 4 months \\
\hline $\begin{array}{l}\text { 2. D. W., } \\
\text { female, } 38\end{array}$ & 22 & $\begin{array}{l}\text { Cipro } \\
\text { Metro } \\
\text { Rifaximin }\end{array}$ & 3 & $5+4+3=12$ & $1+0+1=2$ & $479 /<15$ & $\begin{array}{l}\text { No improvement after } \\
\text { first and second FMT } \\
3 \text { months of remission } \\
\text { after third FMT }\end{array}$ \\
\hline $\begin{array}{l}\text { 3. C. G., } \\
\text { female, } 40\end{array}$ & 58 & $\begin{array}{l}\text { Cipro } \\
\text { Metro }\end{array}$ & 3 & $4+2+3=9$ & $0+1+1=3$ & $849 / 150$ & $\begin{array}{l}\text { Improvement after first } \\
\text { and second FMT } \\
3 \text { months remission } \\
\text { after third FMT }\end{array}$ \\
\hline $\begin{array}{l}\text { 4. H. F., } \\
\text { male, } 26\end{array}$ & 36 & $\begin{array}{l}\text { Cipro } \\
\text { Metro } \\
\text { Rifaximin }\end{array}$ & 3 & $3+4+2=9$ & $0+1+1=2$ & ND & $\begin{array}{l}3 \text { Months remission after } \\
\text { third FMT, then relapse } \\
\text { occurred }\end{array}$ \\
\hline
\end{tabular}

FC, fecal calprotectin; FMT, fecal microbiota transfer; ND, not determined; PDAl, pouchitis disease activity index 


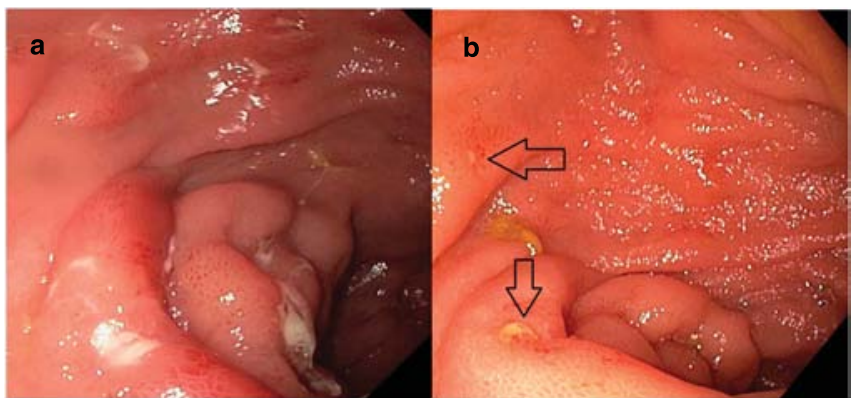

Figure 1. Representative photographies of findings in pouchoscopy. Photographs (a) before and (b) 4 weeks after first FMT in patient 1 . At the second time point, the mucosa was smooth and shiny within the whole pouch, except for two single small ulcerations (about $2 \times 4 \mathrm{~mm}$ ) in the pouch corpus. The ulcerations, marked with arrows, show signs of healing.

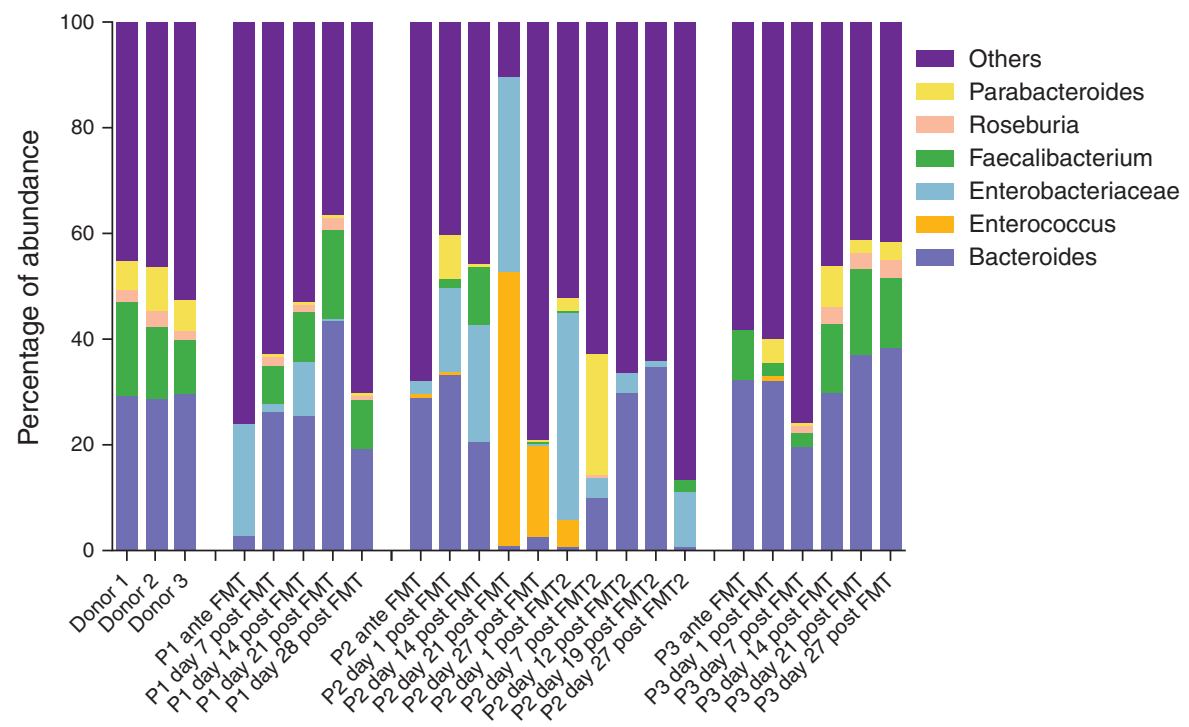

Figure 2. Composition of the pouch microbiota in patients before and after FMT. Taxonomic composition of the stool microbiome on the genus level and at the family level for Enterobacteriaceae phylotypes of the universal donor and of three patients with pouchitis before and after fecal microbiome transfer (FMT). Only selected genera are shown. Patient P1 converged toward a rather stable profile comparable to the donor's microbiotia after FMT, and it demonstrates the best clinical response. Patient P2 did not show such changes until a third FMT that derived from a different donor (data after third FMT not available). The microbiome from patient P3 converged to a profile more comparable to the donor's microbiome 2 weeks after the first FMT. The taxonomic composition was analyzed by deep sequencing of the V1V2 variable regions of the 16S rDNA essentially, as previously described (6).

adding glycerol to a final concentration of $10 \%$ (5). For subsequent FMTs, either fresh stool samples or frozen samples of the same donor were used. This phase 1 , open-label protocol was approved by the local institutional ethics committee.

Within 4 weeks after the last FMT, symptoms resolved in 4 of 5 patients (Table $\mathbf{1}$ ). One patient described an improvement with the reduction of bowel movements, after FMT. Mild transient fever and moderate CRP increase appeared only in one patient after FMT (patient 2). Patients were followed up for a least 3 months post FMT, and sustained response was observed in 3 out of 5 patients. Endoscopic appearance (Figure 1), PDAI, and FC levels decreased, and no further antibiotic treatment courses were necessary in these four patients. and one patient relapsed rapidly 3 months
Deep sequencing of the complete V1V2 regions of the 16S rRNA gene (6) was used to evaluate the taxonomic composition of the stool microbiome. Analysis on the genus level showed distinct patterns of microbial community changes after FMT in the three analyzed patients who had received the same stable donor microbiome (Figure 2). In the responding patients 1 and 3, the stool community composition successfully changed to a structure similar to that of the donor, whereas the nonresponding patient 2 showed a unique pattern distinct from the microbiome of the donor. However, a third FMT that derived from a different donor initiated clinical remission in that patient as well.

In summary, the results of our case series suggest beneficial effects of FMT for patients with chronic antibiotic-dependent pouchitis. Our positive results may have depended on repeated FMT, as remission were observed in 3 of 5 patients after subsequent FMT. Further, we cannot exclude "super donor"-specific effects as described by Moayyedi et al. (1). Although FMT is currently not a standardized and established therapy, this may rapidly change. Advances to facilitate FMT, diminish the invasiveness, and make it more esthetically acceptable are underway. The availability of encapsulated cryopreserved, concentrated, fecal-derived bacteria that may allay many of these concerns is on the horizon $(7,8)$. FMT may therefore be a promising option in chronic pouchitis and other inflammatory diseases; however, controlled and randomized studies are necessary.

\section{CONFLICT OF INTEREST}

The authors declare no conflict of interest.

\section{REFERENCES}

1. Moayyedi P, Surette MG, Kim PT et al. Fecal microbiota transplantation induces remission in patients with active ulcerative colitis in a randomized controlled trial. Gastroenterology 2015;149:102-9.

2. Rossen NG, Fuentes S, van der Spek MJ et al. Findings from a randomized controlled trial of fecal transplantation for patients with ulcerative colitis. Gastroenterology 2015;149:110-8.

3. Landy J, Walker AW, Li JV et al. Variable alterations of the microbiota, without metabolic or immunological change, following faecal microbiota transplantation in patients with chronic pouchitis. Sci Rep 2015;5:12955.

4. Sandborn WJ, Tremaine WJ, Batts KP et al. Pouchitis after ileal pouch-anal anastomosis: 
a Pouchitis Disease Activity Index. Mayo Clin Proc 1994;69:409-15.

5. Satokari R, Mattila E, Kainulainen V et al. Simple faecal preparation and efficacy of frozen inoculum in faecal microbiota transplantation for recurrent Clostridium difficile infection-an observational cohort study. Aliment Pharmacol Ther 2015;41:46-53.

6. Camarinha-Silva A, Jauregui R, Chaves-Moreno $\mathrm{D}$ et al. Comparing the anterior nare bacterial community of two discrete human populations using Illumina amplicon sequencing. Environ Microbiol 2014;16:2939-52.

7. Youngster I, Russell GH, Pindar C et al. Oral, capsulized, frozen fecal microbiota transplantation for relapsing Clostridium difficile infection. JAMA 2014;312:1772-8.

8. Stollman N, Smith M, Giovanelli A et al. Frozen encapsulated stool in recurrent Clostridium difficile: exploring the role of pills in the treatment hierarchy of fecal microbiota transplant nonresponders. Am J Gastroenterol 2015; 110:600-1.

\section{'Department of Internal Medicine IV} (Gastroenterology, Hepatology and Infectious Diseases), University Hospital Jena, Jena, Germany; ${ }^{2}$ Department of Internal Medicine I (Gastroenterology), University Hospital Schleswig-Holstein, Campus Lübeck, Lübeck, Germany; ${ }^{3}$ Microbial Interactions and Processes Research Group, Helmholtz Centre for Infection Research, Braunschweig, Germany. Correspondence: Andreas Stallmach, MD, Department of Internal Medicine IV

(Gastroenterology, Hepatology and Infectious Diseases), University Hospital Jena, Jena 07743,

Germany. E-mail: andreas.stallmach@med.uni-jena.de

\section{Successful}

\section{Endoscopic Pancreatic Necrosectomy in 5-Year-Old Child}

Joan Kheder, MD, $\mathrm{MPH}^{1}$, Samuel Han, $\mathrm{MD}^{1}$ and Wahid Y. Wassef, MD, MPH ${ }^{1}$

doi:10.1038/ajg.2016.9

To the Editor: A 5-year-old boy was undergoing treatment for acute lymphoblastic leukemia with cytarabine, vincristine, pegasparaginase, methotrexate, and dexamethasone. A month following the initiation of therapy, he developed acute pancreatitis, which was felt to be secondary to pegasparaginase. The pancreatitis was complicated by a large peripancreatic fluid collection seen on ultrasound. Ten days later, the patient developed fever and abdominal pain. A computed tomography (CT) scan was performed showing a left upper quadrant organized fluid collection between the pancreas and the posterior gastric wall. The collection measured approximately $7.5 \times 6 \times 9 \mathrm{~cm}$ (Figure 1 ). The patient underwent percutaneous ultrasound guided drainage with the placement of an $8 \mathrm{Fr}$ pigtail catheter into the peripancreatic collection and was treated with antibiotics. The patient had recurrent hospitalizations because of persistent fever and pain, but eventually the symptoms resolved and the drain was removed.

Less than 2 weeks after the drain removal, the patient presented again with abdominal pain and fever. Abdominal CT showed recurrence of the fluid collection adjacent to the pancreatic tail measuring $5 \times 5 \times 5 \mathrm{~cm}$. Ultrasound guided aspiration of the fluid collection showed thick green fluid. Cultures grew Enterococcus Faecium. The patient was referred to the gastroenterology service for endoscopic cystgastrostomy/necrosectomy. Endoscopic ultrasound revealed a $45 \mathrm{~mm}$ by $50 \mathrm{~mm}$ peripancreatic fluid collection (Figure 2). Cystgastrostomy was performed by passing a 19-gauge needle through the stomach into the fluid collection; the fluid was cloudy, brown, and watery. A wire was threaded through the needle under fluoroscopic guidance. The track was dilated with a $10-12 \mathrm{~mm}$ then $12-15$ balloons dilators. Four plastic double pigtail stents (one $7 \mathrm{Fr} \times 4 \mathrm{~cm}$ and three $10 \mathrm{Fr} \times 1 \mathrm{~cm}$ ) were placed over the wire to maintain track patency (Figure 3).

Four weeks after the cystgastrostomy, the patient underwent endoscopic necrosectomy (EN). First, the cystgastrostomy track was dilated with a $12-13.5-15 \mathrm{~mm}$ balloon dilator. Subsequently, the pseudocyst was entered with the upper endoscope. Necrosectomy was performed with a variety of endoscopic tools (forceps, Roth nets, and snares) to remove necrotic material until the granulation tissue was reached. Follow-up CT scan showed resolution of the collection, and the cystgastrostomy stents were removed 3 weeks later. The patient continued to be asymptomatic a year post intervention.

Walled-off Pancreatic Necrosis (WOPN) can occur in $1-9 \%$ of all acute pancreatitis

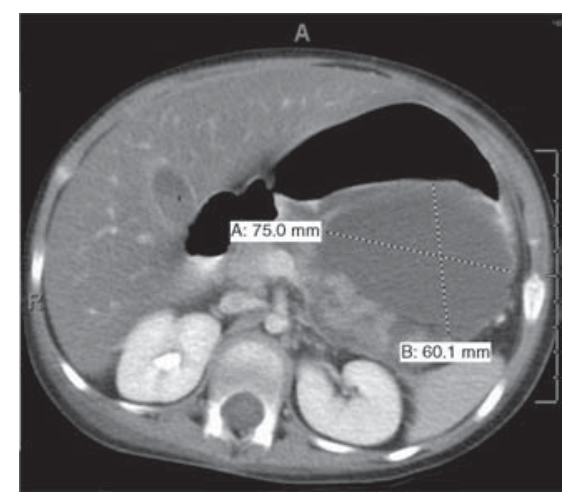

Figure 1. Computed tomography (CT) image showing organized fluid collection in the left upper quadrant between the pancreas and the stomach measuring approximately $7.5 \times 6 \mathrm{~cm}$.

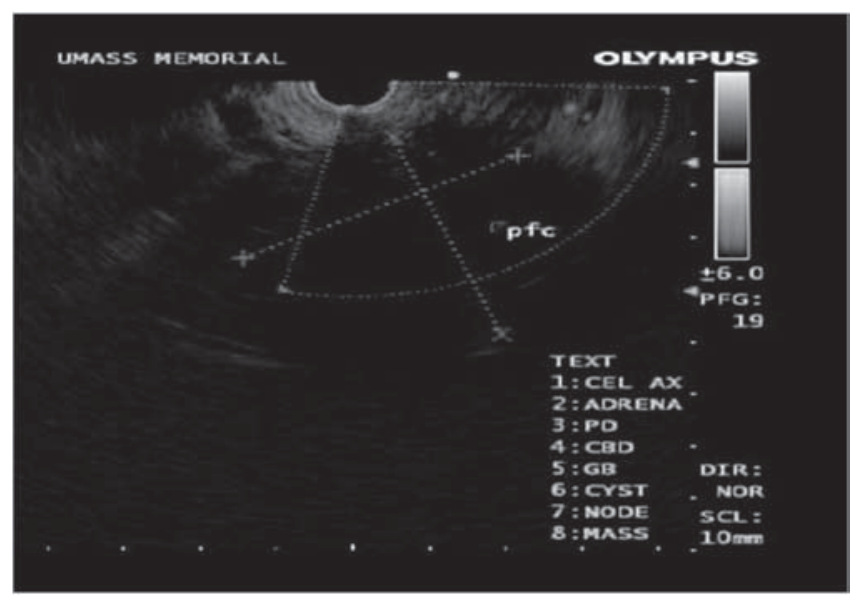

Figure 2. Endoscopic ultrasound (EUS) image showing a peripancreatic fluid collection. 